\title{
Effects of Various Environmental Conditions on Pulcherrimin Production and Extracellular Enzyme Profiles of Metschnikowia pulcherrima
}

\author{
Tülay Turgut Genç
}

\author{
Çanakkale Onsekiz Mart University, Faculty of Arts and Science, Department of Biology, Çanakkale, Turkey
}

\begin{abstract}
The aim of the present study was to determine the effect of various stress conditions on pulcherrimin pigment secretion and extracellular enzyme profiles of isolated Metschnikowia pulcherrima yeast strains. In order to analyse the effects of heat stress and osmotic stress on pulcherrimin pigment synthesis, different temperatures and $\mathrm{NaCl}$ concentrations were used, respectively. The enzymatic profiles of $M$. pulcherrima yeast strains were determined by API-ZYM. The results indicated that the amount of pigment synthesis and the localization were changed depending on the growth conditions. All yeast strains showed a high leucine arylamidase, valine arylamidase, alpha-glucosidase and beta-glucosidase activities.
\end{abstract}

Keywords - Grape, Heat stress, Osmotic stress, Pulcherrimin

\section{Introduction}

Grapes are considered to be a primary source of microorganisms in the wine and winery ecosystems. In recent years, there have been significant studies on the origin of wine yeasts, and the importance of the grapes as a source of these organisms. The number of yeasts on the grape berry, just before the harvest, is between $10^{3}$ and $10^{5}$, depending on the geographical

DOI: $10.18421 /$ SAR31-02

https://doi.org/10.18421/SAR31-02

Corresponding author: Tülay Turgut Genç, Çanakkale Onsekiz Mart University.

Email: tturgutgenc@comu.edu.tr

Received: 29. January 2020.

Revised: 06 March 2020.

Accepted: 12 March 2020.

Published: 30 March 2020.

(c) BY-NC-ND (C) 2020 Tülay Turgut Genç; published by UIKTEN. This work is licensed under the Creative Commons Attribution-NonCommercial-NoDerivs 3.0 License.

The article is published with Open Access at www.sarjournal.com situation of the vineyard, climatic conditions during maturation, the sanitary state of the harvest, and pesticide treatments applied to the vineyard. Yeasts associated with grape / wine ecosystem are usually classified in 15 different yeast genera: Brettanomyces / Dekkera, Hanseniaspora / Kloeckera, Candida, Schizosaccharomyces, Cryptococcus, Debaryomyces, Kluyveromyces, Metschnikowia, Saccharomyces, Saccharomycodes, Pichia, Rhodotorula and Zygosaccharomyces. The most abundant yeast populations are obtained in warm climatic conditions (lower latitudes, elevated temperatures).

Metschnikowia pulcherrima is common on wine grapes at the time of harvest and in grape must during the early stages of wine fermentation [1], [2], [3], [4]. Metschnikowia strains can be effective in protecting fruits against some postharvest pathogens such as Botrytis cinerea [5], [6], [7], [8], [9]. M. pulcherrima produces a red pigment, pulcherrimin that is accumulated in the growth medium around the colonies and within the yeast cells [10]. Pulcherrimin is a large complex formed non-enzymatically from a dibasic acid, pulcherrimic acid, and ferric ions [11], [12].

The aim of the present study was to determine the effect of heat stress and osmotic stress on pulcherrimin pigment secretion and localization, and to determine the extracellular enzyme profiles of $M$. pulcherrima yeast strains isolated from grape berries.

\section{Methods}

The grape samples were aseptically collected from different vineyards in Çanakkale, Turkey. In order to isolate yeast populations, $10 \mathrm{~g}$ of grape berries were mildly homogenized in sterile distilled water. $100 \mu \mathrm{L}$ from the resulting mixture were spread on YGC agar (5 g/L yeast extract, $20 \mathrm{~g} / \mathrm{L}$ glucose, $0.1 \mathrm{~g} / \mathrm{L}$ chloramphenicol, $14.9 \mathrm{~g} / \mathrm{L}$ agar) plates supplemented with $0.1 \%$ sodium propionate and incubated at $30^{\circ} \mathrm{C}$ for 3 days. Randomly selected yeast strains were cultivated in YP medium $(10 \mathrm{~g} / \mathrm{L}$ yeast extract, 20 $\mathrm{g} / \mathrm{L}$ peptone) supplemented with glucose $(20 \mathrm{~g} / \mathrm{L}$ glucose) or sucrose (20 g/L sucrose) and preserved at $-80{ }^{\circ} \mathrm{C}$ for further identification. 
Species identification of the isolated yeasts was done with the API ID32C yeast identification system (Bio Mérieux, Lyon, France) following the manufacturer's suggestions. For molecular identification, the genomic DNA of isolated yeast strains was extracted according to protocol described elsewhere and stored at $-20^{\circ} \mathrm{C}$ until further use [13]. The DNA amplifications were performed in BIORAD Thermal Cycler. The PCR reactions were carried out in a $25 \mu \mathrm{L}$ reaction volume containing Master Mix of PCR Amplification kit (Fermentas, K0171). For amplification of 5.8S-ITS rDNA region ITS1 (5'-TCCGTAGGTGAACCTGCGG-3') and ITS4 (5'-TCCTCCGCTTATTGATATGC-3') primers were used [14]. Gel-Pro Analyser was used for estimating fragment lengths corresponding to the bands of lane. PCR amplicons were purified using GeneJet PCR Purification Kit (Thermo Scientific K0702) and then were digested with HaeIII, HinfI, MspI, HhaI and AluI restriction endonucleases according to supplier's instructions. The restriction fragments were analysed by electrophoresis in 3\% agarose gel and photographed. The length of restriction fragments was calculated by using Gel-Pro Analyser v4.0 software.

In order to determine the effect of heat stress on pigment synthesis and secretion, yeast cells were grown in YPD medium until the early logarithmic stage $\left(\mathrm{OD}_{600}: 0.7-0.8\right)$. After serial dilutions, same amount of yeast cells was spotted either on YPD or YPS plates and incubated at $15{ }^{\circ} \mathrm{C}, 25^{\circ} \mathrm{C}, 30^{\circ} \mathrm{C}, 37$ ${ }^{\circ} \mathrm{C}$ and $45{ }^{\circ} \mathrm{C}$ for 3 days. Similarly, for determining the effect of hyperosmotic stress on pigment production, same amount of logarithmically grown yeast cells were spotted either on YPD or YPS plates supplemented with $0.2 \mathrm{M} \mathrm{NaCl}, 0.4 \mathrm{M} \mathrm{NaCl}, 0.8 \mathrm{M}$ $\mathrm{NaCl}, 1.0 \mathrm{M} \mathrm{NaCl}, 1.2 \mathrm{M} \mathrm{NaCl}$ and1.0 $\mathrm{M} \mathrm{KCl}$. The plates of yeast strains were incubated at $30{ }^{\circ} \mathrm{C}$ for three days. The level of pigment synthesis was evaluated according to localization of pigment and intensity of red colour around the yeast colonies.

The enzymatic activity of the strains tested was assessed by the APIZYM (Bio Mérieux) method. The APIZYM stripes consist of 20 microprobes which enable contact between enzymes and non-soluble substrates. API-ZYM is utilized for screening 19 different enzyme activities: Alkaline phosphatase, Esterase (C 4), Esterase Lipase (C 8), Lipase (C 14), Leucine arylamidase, Valine arylamidase, Cysteine arylamidase, Trypsin, $\alpha$-chymotrypsin, Acid phosphatase, Naphthol-AS-BI-phosphohydrolase, $\alpha$ galactosidase, $\beta$-galactosidase, $\beta$-glucuronidase, $\alpha$ glucosidase, $\quad \beta$-glucosidase, $\quad N$-acetyl- $\beta$ glucosaminidase, $\alpha$-mannosidase, $\alpha$-fucosidase. The activity of the enzymes was expressed in nanomoles of hydrolysed substrate - according to the intensity of the colour reaction on a 5 step scale: 0 means no reaction, 1 means 5 nmol, 2 means 10 nmol, 3 means $20 \mathrm{nmol}, 4$ means $30 \mathrm{nmol}, 5$ means $40 \mathrm{nmol}$ and more.

\section{Results}

Grape is mostly preferred habitat for the yeasts and the natural yeast biota on the grape berries affect the wine production. In our study we specifically isolated the most common yeast species, M. pulcherrima, on grape berries and vine fermentation process. Total yeast population on whole grape berries were changed from $10^{2}$ to $10^{6} \mathrm{CFU} / \mathrm{ml}$. Totally sixty-seven yeast strains were isolated according to red pigment production on glucose or sucrose supplied medium.

All isolated yeast strains were identified by using API ID32C yeast identification system as $M$. pulcherrima. In addition, all genomic DNA of isolated yeast strains were extracted and used for PCR-RFLP analysis. ITS1-5.8S-ITS2 gene region of yeast strains was amplified and cleaved by using HinfI, HaeIII, MspI, AluI and HhaI restriction enzymes. ITS1-5.8S-ITS2 rDNA gene regions of all yeast strains were nearly 400bp in PCR amplicon length. The PCR amplification results of randomly selected 5 yeast strains (MP1, MP4, MP25, MP34 and MP45) were given in Figure 1. The amplified ITS1-5.8S-ITS2 rDNA gene region of yeast strains was cleaved with five enzymes and gave the same restriction profile, except AluI. Therefore, only the PCR-RFLP result of randomly selected yeast strain (MP4) was given in Figure 2. HaeIII and HinfI digestions gave two restriction fragments $290 / 108 \mathrm{bp}$ and 195/195 bp in length, respectively. HhaI and MspI enzyme digestions gave three restriction fragments 215/95/90 bp and 215/120/50 bp in length, respectively. AluI enzyme has no restriction site in amplified ITS1-5.8S-ITS2 rDNA gene region of all yeast strains. The HhaI, HaeIII and HinfI restriction profiles of M. pulcherrima yeast strains was similar to previous results of researches [15], [16], [17], [18], [19]. Therefore, the isolated 67 seven yeast strains were identified as $M$. pulcherrima.

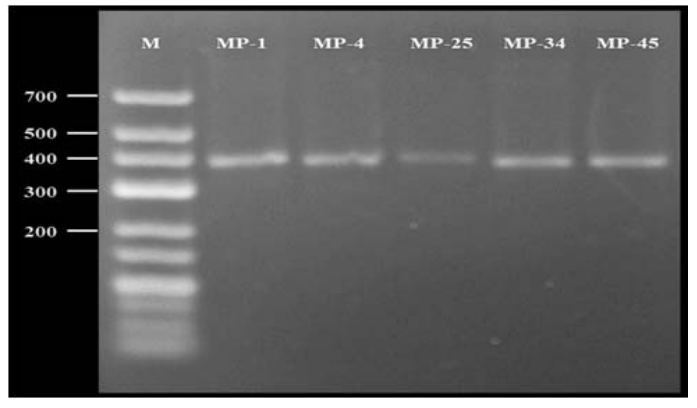

Figure 1. PCR amplification of ITS1-5.8S-ITS2 rDNA gene region. The results of representative MP1, MP4, MP25, MP34 and MP45 yeast strains were given. M: Marker

The pulcherrimin pigment secretion profiles of yeast strains changed depending on the carbon 
sources such as glucose and sucrose. The pulcherrimin synthesis was mainly intracellular in MP1, MP5-7, MP9, MP11, MP15, MP21, MP24-26, MP28-31, MP35-36, MP41, MP46 and MP61 yeast strains when they were grown either in glucose or sucrose. The pigment synthesis was completely intracellular in yeast strains (MP12-13, MP16-19, MP33 and MP67) when they were grown in glucose. Interestingly, in these yeast strains pulcherrimin synthesis was completely abolished when the yeast strains were grown in sucrose. The pigment synthesis in thirty-nine yeast strains (MP2-4, MP8, MP10, MP14, MP20, MP22-23, MP27, MP32, MP34, MP37-40, MP42-45, MP47-60, MP62-65 and MP66) became extracellular when yeast cells were grown in sucrose. The randomly selected two yeast strains from each pigment synthesis and secretion profile were given in Figure 3. These results showed that, in M. pulcherrima yeast strains, the level of pigment synthesis and its localization were changed depending on the carbon source.

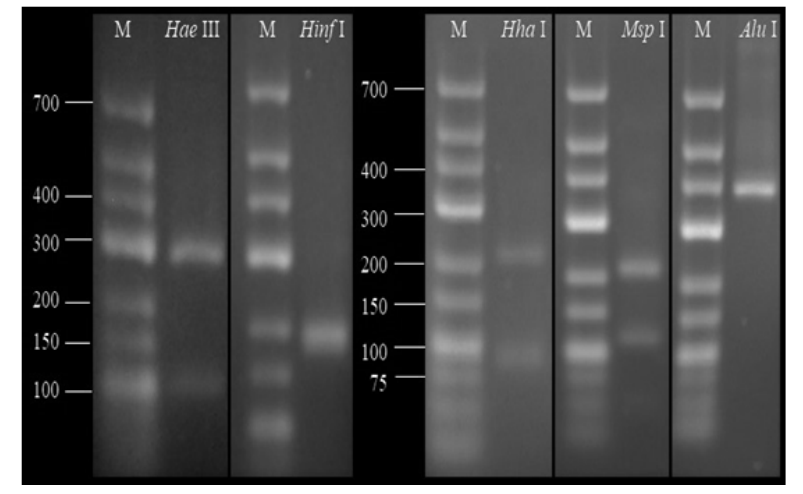

Figure 2. PCR-RFLP result of ITS1-5.8S-ITS2 rDNA gene region. The result of MP4 yeast strain is presented as an example to restriction profile. M: Marker, HaeIII: 290/108 bp, HinfI: 195/195 bp; HhaI: 215/95/90 bp, MspI: 215/120/50 bp, AluI: no cut

For analysing the effect of heat stress on pigment synthesis and secretion, all yeast strains were grown at different temperatures. When the yeast cells incubated at $15{ }^{\circ} \mathrm{C}$, no pigment synthesis was observed in all yeast strains even if the presence of well growth. In addition, the yeast cells cannot show any growth at $45^{\circ} \mathrm{C}$. Therefore, these results were not included in Figure 4. Three yeast strains (MP25, MP26 and MP29) synthesized pulcherrimin pigment at $30^{\circ} \mathrm{C}$ but not at $37^{\circ} \mathrm{C}$. Interestingly, MP34 yeast strain cannot grow at $37^{\circ} \mathrm{C}$. The pigment synthesis of twenty-six yeast strains (MP3, MP10-11, MP20-24, MP28, MP30-32, MP38, MP42-43, MP46-48, MP5155, MP59, MP63 and MP64) was mainly extracellular at $30{ }^{\circ} \mathrm{C}$ and $37{ }^{\circ} \mathrm{C}$. The pigment synthesis of other yeast strains (MP1-2, MP4-9, MP12-19, MP27, MP33, MP35-37, MP3941, MP4445, MP49-50, MP56-58, MP60-62, MP65-66 and MP67) was intracellular at $37{ }^{\circ} \mathrm{C}$. These results indicated that pigment synthesis and localization was changed depending on the growth temperature of $M$. pulcherrima yeast strains.

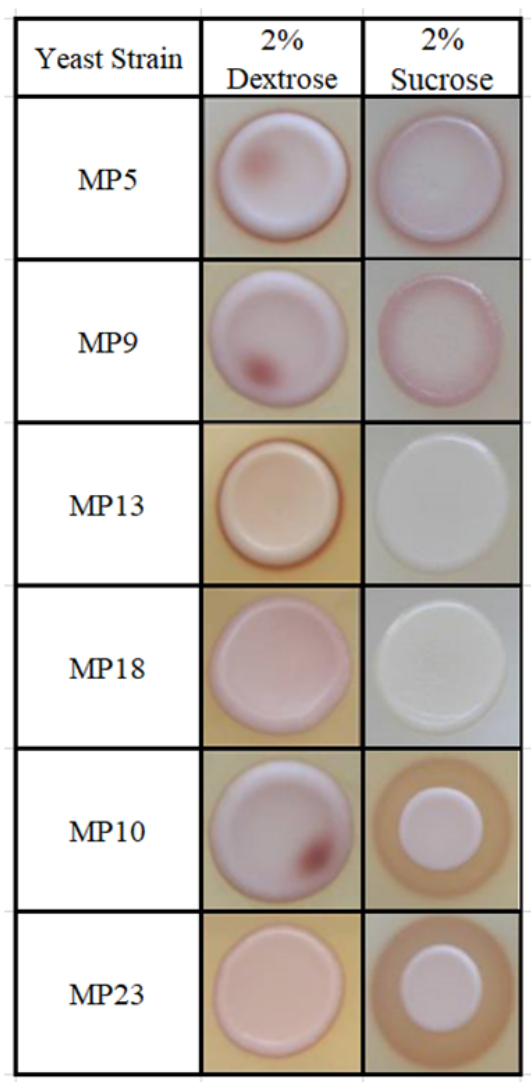

Figure 3. Effect of carbon source on pulcherrimin pigment synthesis and localization

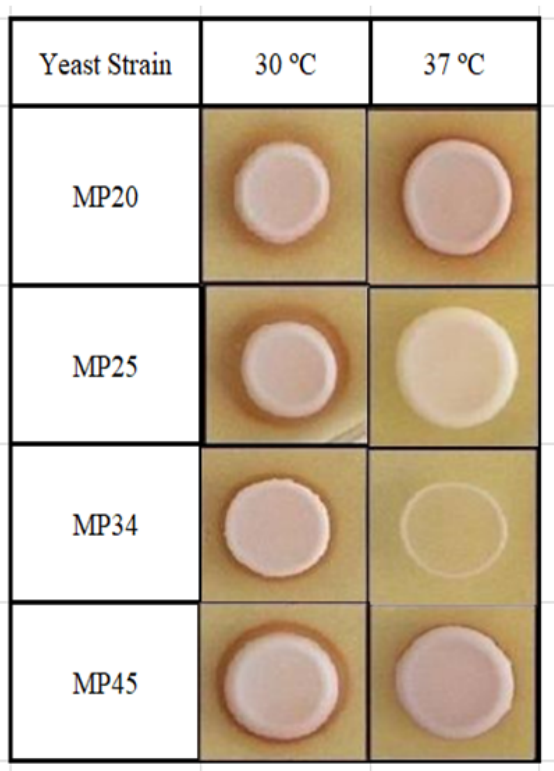

Figure 4. Effect of temperature on pulcherrimin pigment synthesis and localization

In order to determine the effect of hyperosmotic stress on pigment synthesis and secretion, $M$. pulcherrima yeast strains were spotted on plates including various concentrations of $\mathrm{NaCl}$, and incubated at $30{ }^{\circ} \mathrm{C}$ for 3 days. All yeast strains began to accumulate pigment within the cell after $0.4 \mathrm{M}$ 
$\mathrm{NaCl}$ concentrations (Figure 5). Only two yeast strains, MP20 and MP32, did not produce pulcherrimin pigment in $1.2 \mathrm{M} \mathrm{NaCl}$ concentration. Other yeast strains synthesized pulcherrimin pigment in all $\mathrm{NaCl}$ concentrations. These results indicated that, hyperosmotic stress triggers the accumulation of pulcherrimin pigment with in the yeast cells, and the pigment synthesis in some yeast cells was inhibited at higher concentration of salt (above $1.4 \mathrm{M} \mathrm{NaCl}$, data not given).

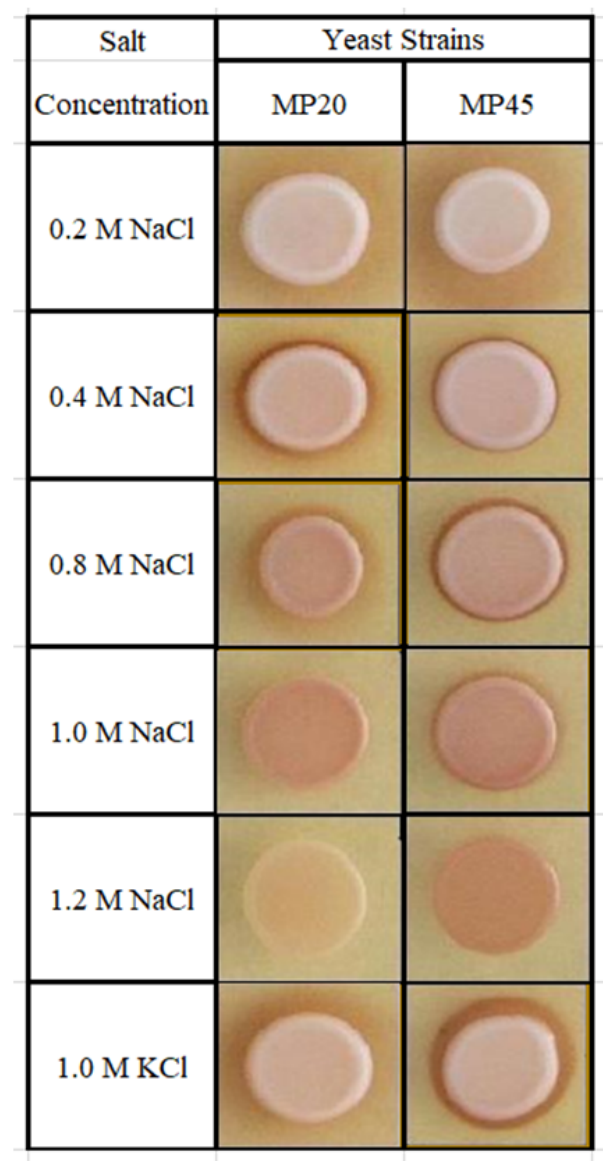

Figure 5. Effect of hyperosmotic stress on pulcherrimin pigment synthesis and localization

The extracellular enzyme activities of $M$. pulcherrima yeast strains were detected by using semi-quantitative test system, API-ZYM, which utilizes for screening 19 different enzyme activities. The extracellular enzyme profiles of all sixty-seven M. pulcherrima yeast strains were tested and grouped in five different profiles. According to API-ZYM test results, the yeast strains were grouped in five different enzyme profiles and the list of yeast strains were given in Table 1. The results of five yeast strains representing each enzyme profile were given in Figure 6. All of the yeast strains showed good enzymatic activity for leucine arylamidase, valine arylamidase, alpha-glucosidase and beta-glucosidase. In contrast, no enzymatic activity was detected for trypsin, alpha-chymotrypsin, alpha-galactosidase, beta- galactosidase, beta-glucuronidase, $\mathrm{N}$-acetylbeta-glucosaminidase, alpha-mannosidase and alpha- fucosidase. The occurrence of lipase (C14), esterase lipase (C8), cystine arylamidase, alkaline phosphatase and naphthol-ASBI-phosphohydrolase was low and the enzyme activities ranged from 10 to $30 \mathrm{nmol}$ between the strains. All tested $M$. pulcherrima yeast strains had leucine arylamidase (50 nmol) and valine arylamidase (between 40 to 50 nmol) activity (Figure 6).

Table 1. Extracellular enzyme profile of M. pulcherrima yeast strains

\begin{tabular}{|c|c|}
\hline $\begin{array}{c}\text { Enzyme Profile } \\
\text { Groups }\end{array}$ & Yeast Strains \\
\hline Group I & $\begin{array}{l}\text { MP1, MP5, MP6, MP7, MP9, } \\
\text { MP11, MP15, MP24, MP25, MP29, } \\
\text { MP35, MP36, MP41 }\end{array}$ \\
\hline Group II & $\begin{array}{l}\text { MP2, MP4, MP14, MP21, MP22, } \\
\text { MP26, MP27, MP28, MP 30, MP31, } \\
\text { MP32, MP34, MP37, MP39, MP40, } \\
\text { MP61, MP62 }\end{array}$ \\
\hline Group III & $\begin{array}{l}\text { MP3, MP8, MP10, MP20, MP23, } \\
\text { MP38, MP42, MP43, MP44, MP45, } \\
\text { MP47, MP48, MP49, MP50, MP51, } \\
\text { MP52, MP53, MP54, MP55, MP56, } \\
\text { MP57, MP58, MP59, MP60, MP63, } \\
\text { MP64, MP65, MP66 }\end{array}$ \\
\hline Group IV & MP12, MP33, MP67 \\
\hline Group V & MP13, MP16, MP17, MP18, MP19 \\
\hline
\end{tabular}

\section{Conclusion}

Among the various fruits, the grape berry surfaces provide an optimal and nutrient-rich environment for M. pulcherrima yeast species. M. pulcherrima is a potential biological control agent because of its ability to produce insoluble red pigment. The pulcherrimin pigment exhibits strong antifungal activity against post-harvest plant pathogenic fungi such as Botrytis cinerea. When the pigment synthesized, the colonies become a more intense brownish colour, indicator of intracellular pulcherrimin production, and sometimes the colonies surrounded with a pinkish halo, indicator of extracellular pigment production. The antifungal activity of M. pulcherrima yeast species is related to the production of pulcherrimin pigment [20], [21], [22].

In our research we analysed the effects of various conditions on pulcherrimin pigment production and its localization. It is previously reported that $M$. pulcherrima yeast strains can use different sugars (glucose, sucrose, fructose, galactose and maltose) as a carbon source except lactose [23]. In our research, we showed that $M$. pulcherrima yeast strains can grow on glucose and sucrose well, but the pigment production and localization was different. Some yeast strains can produce pigment in dextrose but not in sucrose, or vice versa. Similarly, in some yeast 
cells pigment production is intracellular while in others it is extracellular. Therefore, the pulcherrimin pigment production and cellular localization was changed depending on the carbon sources.

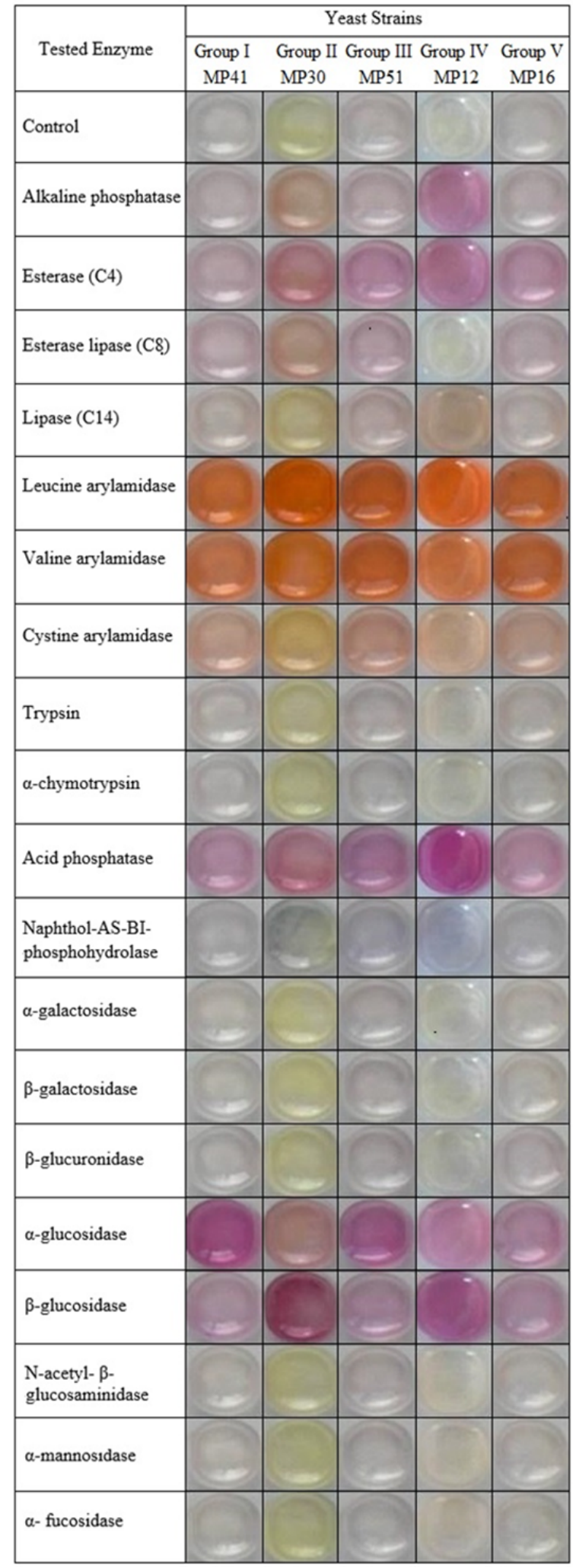

Figure 6. The extracellular enzyme activities of $M$. pulcherrima yeast strains. Five yeast strains resembling each enzyme profile were selected and given
M. pulcherrima yeast strains can grow properly under low temperatures $\left(15-20^{\circ} \mathrm{C}\right)$ and $\mathrm{pH}$ conditions (3-6) [24]. Similarly, all yeast strains can grow at 37 ${ }^{\circ} \mathrm{C}$, but no pigment synthesis was recorded. Previously reported that $M$. pulcherrima yeast strains cannot grow in glucose supplied medium at $37{ }^{\circ} \mathrm{C}$ [25]. But in our results all yeast cells, except MP34, can grow at $37{ }^{\circ} \mathrm{C}$ both in glucose and sucrose. In addition to these results, the localization of pigment was changed depending on the growth temperature, $30{ }^{\circ} \mathrm{C}$ or $37^{\circ} \mathrm{C}$. Our results indicated that in of $M$. pulcherrima yeast strains, the pigment production and cellular localization were changed depending on the growth temperature.

In the present study, we examined the effect of osmotic stress on pigments synthesis by using different salt concentrations. All yeast strains synthesized pulcherrimin pigment in all salt concentrations, except two yeast strains which were not produce pigment at $1.2 \mathrm{M} \mathrm{NaCl}$ concentration. These results indicated that, hyperosmotic stress triggers the accumulation of pulcherrimin pigment with in the yeast cells up to a certain concentration $(\geq 1.2 \mathrm{M} \mathrm{NaCl})$.

The extracellular enzyme activities of $M$. pulcherrima yeast strains are important for production of different esters and aroma during wine production. The pectinase, protease, glucanase, lichenase, $\beta$-glucosidase, cellulase, xylanase, amylase, sulphite reductase and lipase and $\beta$-lyase enzyme activities of $M$. pulcherrima yeast strains were previously reported [26], [27], [28], [29]. In our research we determine the extracellular enzyme profile of $M$. pulcherrima yeast strains qualitatively by using API-ZYM test. All yeast strains showed good enzymatic activity for leucine arylamidase, valine arylamidase, alpha-glucosidase and betaglucosidase. Leucine arylamidase (LAP) or leucine aminopeptidase is a proteolytic enzyme that catalyses the hydrolysis of peptides containing leucine. This activity may be related with the pulcherrimin pigment production and localization in $M$. pulcherrima yeast strains. The different enzymatic profiles may provide a useful and rapid differentiation of species with in the genus. Therefore, new studies have to be conducted by using more isolates from the same species and additional novel techniques have to be used for confirmations.

\section{Acknowledgements}

This work was supported by Çanakkale Onsekiz Mart University The Scientific Research Coordination Unit, Project number: FYL-2010-197. The authors declare that they have no conflict of interests. 


\section{References}

[1]. Clemente-Jimenez, J. M., Mingorance-Cazorla, L., Martínez-Rodríguez, S., Las Heras-Vázquez, F. J., \& Rodríguez-Vico, F. (2004). Molecular characterization and oenological properties of wine yeasts isolated during spontaneous fermentation of six varieties of grape must. Food Microbiology, 21(2), 149-155.

[2]. Combina, M., Elía, A., Mercado, L., Catania, C., Ganga, A., \& Martinez, C. (2005). Dynamics of indigenous yeast populations during spontaneous fermentation of wines from Mendoza, Argentina. International journal of food microbiology, 99(3), 237-243.

[3]. Fleet, G. H. \& Heard, G. M. (1993). Yeasts: growth during fermentation, p. 27-54. In G. H. Fleet (ed.), Wine microbiology and biotechnology. Harword Academic Publishers, Philadelphia.

[4]. Mills, D. A., Johannsen, E. A., \& Cocolin, L. (2002). Yeast diversity and persistence in botrytis-affected wine fermentations. Appl. Environ. Microbiol., 68(10), 4884-4893.

[5]. De Curtis, F., Torriani, S., Rossi, F., \& De Cicco, V. (1996). Selection and use of Metschnikowia pulcherrima as a biological control agent for postharvest rots of peaches and table grapes. Annali di microbiologia ed enzimologia, 46, 45-55.

[6]. Piano, S., Neyrotti, V., Migheli, Q., \& Gullino, M. L. (1997). Biocontrol capability of Metschnikowia pulcherrima against Botrytis postharvest rot of apple. Postharvest Biology and Technology, 11(3), 131-140.

[7]. Qin, G., Tian, S., \& Xu, Y. (2004). Biocontrol of postharvest diseases on sweet cherries by four antagonistic yeasts in different storage conditions. Postharvest biology and technology, 31(1), 51-58.

[8]. Spadaro, D., Vola, R., Piano, S., \& Gullino, M. L. (2002). Mechanisms of action and efficacy of four isolates of the yeast Metschnikowia pulcherrima active against postharvest pathogens on apples. Postharvest Biology and Technology, 24(2), 123-134.

[9]. Karabulut, O. A., Smilanick, J. L., Gabler, F. M., Mansour, M., \& Droby, S. (2003). Near-harvest applications of Metschnikowia fructicola, ethanol, and sodium bicarbonate to control postharvest diseases of grape in central California. Plant Disease, 87(11), 1384-1389.

[10]. Kluyver, A. J., Van Der Walt, J. P., \& Van Triet, A. J. (1953). Pulcherrimin, the pigment of Candida pulcherrima. Proceedings of the National Academy of Sciences of the United States of America, 39(7), 583593.

[11]. Cook, A. H., \& Slater, C. A. (1956). 798. The structure of pulcherrimin. Journal of the Chemical Society (Resumed), 4133-4135.
[12]. MacDonald, J. C. (1965). Biosynthesis of pulcherriminic acid. Biochemical Journal, 96(2), 533538.

[13]. Sherman, F., Fink, G. R. \& Hicks, J. B. (1986). Methods in yeast genetics, Cold Spring Harbor, NY: Cold Spring Harbor Laboratory.

[14]. White, T. J., Bruns, T., Lee, S. J. W. T., \& Taylor, J. (1990). Amplification and direct sequencing of fungal ribosomal RNA genes for phylogenetics. PCR protocols: a guide to methods and applications, 18(1), 315-322.

[15]. Guillamón, J. M., Sabaté, J., Barrio, E., Cano, J., \& Querol, A. (1998). Rapid identification of wine yeast species based on RFLP analysis of the ribosomal internal transcribed spacer (ITS) region. Archives of Microbiology, 169(5), 387-392.

[16]. Esteve-Zarzoso, B., Belloch, C., Uruburu, F., \& Querol, A. (1999). Identification of yeasts by RFLP analysis of the $5.8 \mathrm{~S}$ rRNA gene and the two ribosomal internal transcribed spacers. International Journal of Systematic and evolutionary microbiology, 49(1), 329-337.

[17]. Capece, A., Siesto, G., Romaniello, R., \& Romano, P. (2009). Restriction analysis of rDNA regions to differentiate non-Saccharomyces wine species in mixed cultures. J Eng Technol Res, 1(4), 068-071.

[18]. Baffi, M. A., dos Santos Bezerra, C., ArévaloVillena, M., Briones-Pérez, A. I., Gomes, E., \& Da Silva, R. (2011). Isolation and molecular identification of wine yeasts from a Brazilian vineyard. Annals of microbiology, 61(1), 75-78.

[19]. Pham, T., Wimalasena, T., Box, W. G., Koivuranta, K., Storgårds, E., Smart, K. A., \& Gibson, B. R. (2011). Evaluation of ITS PCR and RFLP for differentiation and identification of brewing yeast and brewery 'wild'yeast contaminants. Journal of the Institute of Brewing, 117(4), 556-568.

[20]. Sipiczki, M. (2006). Metschnikowia strains isolated from botrytized grapes antagonize fungal and bacterial growth by iron depletion. Appl. Environ. Microbiol., 72(10), 6716-6724.

[21]. Türkel, S., \& Ener, B. (2009). Isolation and characterization of new Metschnikowia pulcherrima strains as producers of the antimicrobial pigment pulcherrimin. Zeitschrift für Naturforschung C, 64(56), 405-410.

[22]. Oro, L., Ciani, M., \& Comitini, F. (2014). Antimicrobial activity of $\mathrm{M}$ etschnikowia pulcherrima on wine yeasts. Journal of applied microbiology, 116(5), 1209-1217.

[23]. Loira, I., Morata, A., Bañuelos, M. A. \& SuárezLepe, J. A. (2019). Isolation, selection and identification techniques for non-Saccharomyces yeasts of oenological interest. In Biotechnological Progress and Beverage Consumption; Volume 19: The Science of Beverages; Grumezescu, A., Holban, A. M., Eds.; Elsevier Academic Press: Cambridge, MA, USA, Chapter 15. 
[24]. Santamauro, F., Whiffin, F. M., Scott, R. J., \& Chuck, C. J. (2014). Low-cost lipid production by an oleaginous yeast cultured in non-sterile conditions using model waste resources. Biotechnology for biofuels, 7(1), 34 .

[25]. Morata, A., Loira, I., Escott, C., del Fresno, J. M., Bañuelos, M. A., \& Suárez-Lepe, J. A. (2019). Applications of Metschnikowia pulcherrima in Wine Biotechnology. Fermentation, 5(3), 63.

[26]. Barbosa, C., Lage, P., Esteves, M., Chambel, L., Mendes-Faia, A., \& Mendes-Ferreira, A. (2018). Molecular and phenotypic characterization of Metschnikowia pulcherrima strains from Douro wine region. Fermentation, 4(1), 8.
[27]. Jolly, N. P., Augustyn, O. P. H., \& Pretorius, I. S. (2006). The role and use of non-Saccharomyces yeasts in wine production. South African Journal of Enology and Viticulture, 27(1), 15-39.

[28]. Ganga, M. A., \& Martínez, C. (2004). Effect of wine yeast monoculture practice on the biodiversity of nonSaccharomyces yeasts. Journal of Applied Microbiology, 96(1), 76-83.

[29]. Reid, V. J., Theron, L. W., du Toit, M., \& Divol, B. (2012). Identification and partial characterization of extracellular aspartic protease genes from Metschnikowia pulcherrima IWBT Y1123 and Candida apicola IWBT Y1384. Appl. Environ. Microbiol., 78(19), 6838-6849. 